CDD: 025.567

\title{
O COMPORTAMENTO INFORMACIONAL NO ESTÁGIO CURRICULAR
}

THE INFORMATION BEHAVIOR IN TRAINEESHIP

\author{
Sandra Regina Moitinho Lage ${ }^{1}$ \\ Patricia Santana ${ }^{2}$ \\ Linete Bartalo ${ }^{3}$ \\ Carlos Alberto Ávila Araújo ${ }^{4}$
}

Resumo: Com o objetivo de investigar o comportamento informacional no desenvolvimento do estágio curricular obrigatório dos alunos de um curso de graduação em Biblioteconomia, realizou-se este estudo. Um questionário foi aplicado para 20 estagiários, investigando as suas necessidades de informação, as formas e as fontes em que buscam a informação e o uso que dela fazem. Dentre os principais resultados, constatou-se que os participantes percebem a relação da teoria aprendida em sala de aula quando enfrentam situações no ambiente de estágio, e que este ambiente sempre possibilita a interação na troca de conhecimentos e experiências. A fonte de informação mais utilizada no desenvolvimento das atividades no estágio são os colegas de sala de aula. No entanto, a internet, livros, artigos e os professores merecem destaque. Para muitos participantes, o estágio contribuiu de alguma forma, atendendo às expectativas para aquisição de novos conhecimentos e experiências práticas importantes.

Palavras-chave: Comportamento informacional. Estágio curricular. Ambiente de estágio. Formação profissional. Biblioteconomia.

Abstract: Aiming to investigate the information behavior in the development stage of the compulsory curriculum of the students of a graduate course in librarianship, this study took place. A questionnaire was administered to 20 trainees, investigating their needs for information, forms and sources they seek information and how they use it. Among the main results, it was found that participants perceived the relationship of theory learned in the classroom when faced with situations in the stage environment and that this environment always allows interaction in the exchange of knowledge and experiences. The main source of information used in the development of the activities on stage are fellow classroom. However , the internet, books, articles, and teachers are noteworthy. For many participants, the stage has contributed in some way, meeting the expectations for the acquisition of important new knowledge and practical experience.

Keywords: Information behavior. Traineeship. Setting the stage. Vocational training. Librarianship.

\footnotetext{
${ }^{1}$ Universidade Estadual de Londrina-UEL. Mestranda do Curso de Ciência da Informação. Brasil. Email: lage@sercomtel.com.br

${ }^{2}$ Universidade Estadual de Londrina - UEL. Aluna especial do Programa de Pós-Graduação em Ciência da Informação-UEL (Mestrado). Brasil. E-mail: paty.sant13@ hotmail.com

${ }^{3}$ Universidade Estadual de Londrina-UEL. Professora do Departamento de Ciência da Informação e do Programa de Pós-Graduação em Ciência da Informação-UEL. Brasil. E-mail: linete@ @el.br

${ }^{4}$ Universidade Federal de Minas Gerais - UFMG. Pós-Doutor pela Universidade do Porto, Portugal (2011). Professor adjunto IV da Escola de Ciência da Informação da UFMG. Brasil E-mail: casalavila@yahoo.com.br
}

Recebido em: 10/03/2013 - Aceito em: 19/09/2013. 


\section{INTRODUÇÃO}

As primeiras contemplações em relação ao estágio, segundo Angnes, Lima e Paula (2010), ocorreram em 1972, no I Encontro de Professores de Didática na Universidade de Brasília. Neste encontro, observou-se que o estágio seria obrigatório aos estudantes com o intuito de sua inserção no mercado de trabalho para iniciar contato prévio com a profissão almejada.

A Lei $n^{\circ} 11.778$ de 25 de setembro de 2008 estabeleceu subsídios necessários à formação técnico profissional e salienta que o estágio é um ato educativo desenvolvido no ambiente de trabalho com o objetivo de preparar o educando para a vida cidadã. O estagiário deve desenvolver no ambiente de estágio, atividades equiparadas para a previsão do projeto pedagógico. O mesmo será observado por um profissional, da própria empresa, com formação e experiência profissional na área a ser desenvolvida. Enfim, a Lei em questão oferece subsídios de suporte para o desenvolvimento das atividades tanto na Instituição de Ensino,a parte concedente e o estagiário.

Bianchi (2011) menciona que o estágio realiza-se em ambientes que proporcionam experiências práticas na formação, devendo o estudante estar em condições de estagiar, de acordo com o definido pela respectiva instituição de ensino. Existem instituições que são credenciadas e encaminham os alunos, por meio de convênios, com o objetivo de proporcionar um vínculo maior entre escola/trabalho.

Segundo a autora, o estágio deixou de ser um ato formal para ser uma atividade de grande aprendizagem, um meio de inserir o aluno na realidade de sua profissão. A exigência nos currículos superiores é que, tanto o aluno, quanto o docente tenham um estreito espaço entre a teoria e a prática. Nesta perspectiva, observa-se que o estágio é um exercício de pesquisa que resulta na experiência profissional do aluno.

Salienta-se que, antes de iniciar o estágio, é necessário que o aluno entenda bem a importância desta atividade e o significado do que é a palavra 'estágio'. Para Bianchi (2011, p.7), o estágio é “o período de estudos práticos, exigido dos candidatos ao exercício de certas profissões liberais [...], durante o qual uma pessoa exerce uma atividade temporária numa empresa". 
Neste sentido, Bousso et. al. (2000, p. 220) observam que "professores e alunos trabalham em aliança, onde o conteúdo é a matéria prima da aprendizagem, e o que é feito do conteúdo depende do processo vivido pela pessoa do aluno". Segundo Perelló (1998, apud Bousso et. al., 2000, p. 222), a importância do estágio será o "parâmetro onde teorias e técnicas educacionais revelarão o profissional do futuro [...] e, especialmente como cidadão que sabe construir seu mundo e sabe fazer sua história, sendo um sujeito atuante".

Bianchi (2011) apresenta fatores fundamentais que se pretende alcançar no estágio, tais como, aplicar na prática o que aprendeu em sala de aula, e avaliar a possibilidade de sugerir mudanças na empresa viabilizando a solução de problemas.

Piconez (2001) também expressa que a prática de estágio amplia as características política, epistemológica e profissional, e são as atividades teóricas e práticas que envolvem a totalidade das ações do currículo do aluno.

Alarcão (1996) observa que o estágio é uma ocasião em que os estudantes estão diretamente em contato com profissionais da área, a fim de ampliar seu conhecimento e até mesmo obter uma reflexão a partir da sua futura ação profissional. É por meio do estágio que os estudantes têm a possibilidade de relacionar os assuntos abordados em sala de aula com a prática, sendo uma importante fonte de aprendizagem e experiência, principalmente para os que já estão atuando na área. Neste sentido, Burriolla (1995, p. 17) afirma que o estágio deve permitir ao aluno

[...] o preparo efetivo para o agir profissional: a possibilidade de um campo de experiência, a vivência de uma situação social concreta [...] que lhe permitirá uma revisão constante desta vivência e o questionamento de seus conhecimentos, habilidades, visões de mundo etc., podendo levá-lo a uma inserção crítica e criativa na área profissional e um contexto histórico mais amplo.

O estágio, segundo Bianchi (2011), é uma atividade que depende exclusivamente da dedicação do aluno, porquanto esta é a oportunidade que o acadêmico tem para desenvolver sua carreira profissional,ou seja, o "estágio representa para o aluno uma oportunidade de verificar o acerto de uma escolha profissional, já que é o momento em que a situação ensino-aprendizagem se realiza em toda sua plenitude" (PONTUSCHKA, 1991, p. 136). 
Reforça-se que a atividade de estágio deve ser uma ação planejada, um processo contínuo, dinâmico e sistemático com periodicidade, perseguindo metas que levem à formação adequada com o objetivo de estimular o potencial do estagiário por meio das atividades de ensino-aprendizagem. Observa-se que a instituição tem o compromisso social de transmitir a informação, criando valores éticos para o desenvolvimento de dimensões do ser humano, considerando suas capacidades, bem como o comportamento informacional no que tange à busca e à utilização da informação para suprir uma determinada necessidade.

Alarcão (1996) ressalta que as experiências vividas no estágio desenvolve a melhoria da prática profissional. Os conhecimentos adquiridos na prática e a troca de experiências são considerados as melhores formas de aprendizagem. Assim, o estagiário em sua construção tem de ser capaz de interpretar o que se vê, de imitar sem copiar, de recriar e de transformar.

Burriolla (apud BIANCHI, 2011) parte da concepção de que o estágio é imprescindível para a formação do aluno. É o momento em que desenvolve a aprendizagem prática, o papel profissional, a responsabilidade, o compromisso, o espírito crítico, a consciência, a criatividade e as habilidades profissionais esperadas na formação deste aluno, levando-se em conta os processos que influenciam o comportamento do indivíduo quando se busca e usa a informação.

\section{COMPORTAMENTO INFORMACIONAL NO ESTÁGIO}

A busca e o uso de informação têm sido uma preocupação em pesquisas realizadas nas áreas de Biblioteconomia e da Ciência da Informação, as englobam situações de busca e uso de informação, "desde estudos de grupos de usuários específicos de determinados sistemas de informação, até aqueles cujo foco é o indivíduo e suas necessidades de informação, decorrentes da vida cotidiana" (SILVA, 2010, p. 14).

$\mathrm{Na}$ atual sociedade globalizada e em constante modificação, o acesso à informação é de suma importância para os diversos profissionais que necessitam de tal insumo para obter sucesso em suas atividades profissionais. A informação é vista como algo construído pelo indivíduo, obtendo sentido quando integrada a um 
contexto, considerando-se que “este indivíduo é uma pessoa com um repertório cultural de conhecimentos, crenças e valores, com necessidades cognitivas, afetivas e fisiológicas próprias" (PEREIRA, 2010, p.179). Os estudos de usuários têm como objetivo descobrir o que os indivíduos precisam em matéria de informação, assim como compreender se as necessidades de informação estão sendo satisfatórias.

Nesse sentido Amaral, Araújo e Silva, (2010, p. 3-4) afirmam que

Usuários são indivíduos compostos por necessidade cognitivas, inseridos em um ambiente político, econômico e social que influenciam na necessidade de informação. Tal necessidade é identificada quando o indivíduo percebe que seus conhecimentos sobre determinado assunto encontram-se insuficientes para lidar com a incerteza, conflito ou demandas surgidas em sua área de estudo ou trabalho.

Para Choo (2003), o estudo da necessidade e do uso da informação deve englobar a experiência humana - pensamentos, sentimentos, ações e o ambiente onde a informação é processada e utilizada. Em relação aos elementos que influenciam o comportamento do indivíduo, o autor observa que se baseia em três estágios - a necessidade de informação, a busca de informação e o uso da informação.

A necessidade de informação filtra-se pelos vários níveis de consciência do indivíduo, do visceral ao consciente e ao formal, neste sentido o indivíduo questionase por meio de perguntas, podendo ser apresentado a um sistema de informação.

Segundo Wilson (2006, p. 659-660), quando o indivíduo percebe a necessidade de informação, pode utilizar

[...] sistemas formais costumeiramente definidos como sistemas de informação ou a sistemas que podem ter funções de informar em adição à sua função principal que é a de não informar (tais como, imobiliárias ou lojas de venda de carro, em que ambas dizem respeito à atividade de venda, mas podem ser utilizadas para obter informação sobre preços, áreas de habitação adequadas) [...].

De acordo com Choo (2003), a maneira como a informação ganha importância dependerá das estruturas cognitivas e emocionais do indivíduo. O comportamento de busca da informação é um processo humano e social, uma junção de atividades por meio das quais a informação torna-se útil para um indivíduo ou grupo. O ambiente onde a informação é buscado é analisado - o ambiente interno de processamento da 
informação, que está dentro do indivíduo e o ambiente externo onde a informação é usada, que é o ambiente profissional do indivíduo.

Choo (2003) observa que a necessidade, a busca e o uso da informação ocorrem em ciclos recorrentes, que interagem sem ordem predeterminada. O processo de busca e uso da informação interage com elementos cognitivos, emocionais e situacionais do ambiente. De forma contínua, esses elementos estimulam o processo de busca da informação, alterando a compreensão do indivíduo sobre o papel da informação e sobre os comportamentos em relação a ela, como também os critérios pelos quais o valor da informação é determinado.

Salienta o autor que, no estágio da busca de informação, o indivíduo desenvolve uma compreensão clara da necessidade de informação e pode ser influenciado por fatores cognitivos, emocionais e situacionais. As características profissionais e do meio social podem instigar ou limitar determinados comportamentos de busca da informação, como também a estrutura hierárquica e o grupo de trabalho influenciarão as atitudes do indivíduo em relação à coleta de informação.

Segundo Wilson (1999, p. 263), o termo comportamento de busca de informação está relacionado "à variedade de métodos que os indivíduos utilizam para descobrir e ter acesso a fontes de informações”. Wilson (2000) ressalta que vários fatores referentes à estrutura organizacional e às atividades desenvolvidas relacionadas ao trabalho podem influenciar o comportamento de busca de informação dos indivíduos.

O uso da informação é o estágio final da abordagem de Choo (2003). É a seleção e o processamento das informações que resultam em novos conhecimentos ou ações. O indivíduo, nesta etapa, está atuando na informação encontrada, podendo responder ao seu questionamento, solucionar o problema, tomar decisões, negociar uma posição ou dar sentido a uma situação. A relevância da informação e o seu efetivo uso dependerão de como o indivíduo avalia cognitivamente e emocionalmente a informação recebida, inclusive os atributos objetivos capazes de determinar a pertinência da informação a uma determinada situação problemática. O modelo 
identifica oito classes de uso da informação: esclarecimento, compreensão do problema, instrumental, factual, confirmativa, projetiva, motivacional e pessoal ou política. A partir do momento em que a busca consegue gerar informações satisfatórias, o indivíduo apresenta sentimento de confiança. Por outro lado, se a informação não for útil, o resultado são sentimentos de decepção e frustração.

Gasque e Costa (2010, p. 31-32) salientam que o comportamento informacional é visto como

[...] processo natural do ser humano no papel de aprendiz da própria vida, requer visão ampla do pesquisador. Exige, ainda, o entendimento das relações estabelecidas em determinado espaço-tempo em que ocorrem ações de busca, uso e transferência de informação. Os indivíduos se engajam nessas ações quando têm necessidade de informação.

Nesta perspectiva Davenport (1998, p. 110) reforça que

[...] comportamento informacional se refere ao modo como os indivíduos lidam com a informação. Inclui a busca, o uso, a alteração, a troca, o acúmulo e até mesmo o ato de ignorar os informes. Consequentemente, quando administramos o comportamento ligado à informação, tentamos aperfeiçoar a eficácia global de um ambiente informacional por meio de uma ação combinada.

De acordo com Gasque e Costa (2010), o comportamento informacional é uma totalidade do comportamento humano em relação ao uso de fontes e canais de informação, incluindo a busca da informação passiva ou ativa; a atividade ou ação de buscar informação em consequência da necessidade de atingir um objetivo; o nível micro do comportamento em que o indivíduo interage com sistemas de informação de todos os tipos, constituindo o conjunto dos atos físicos e mentais e envolve a incorporação da nova informação aos conhecimentos prévios do indivíduo.

\section{CURSO DE BIBLIOTECONOMIA E O BIBLIOTECÁRIO}

A Lei de Diretrizes e Bases da educação nacional conduz o encaminhamento das práticas educacionais gerais, e as Diretrizes Curriculares para os cursos de Biblioteconomia, aprovadas em 03/04/2001 pelo parecer $n^{\circ}$ 492/2001CNE/CES (Brasil, 2001), estabelecem as diretrizes para a formação do Bibliotecário para que esteja preparado para enfrentar com proficiência e criatividade os problemas de sua 
prática profissional, produzindo e difundindo conhecimentos, refletindo criticamente sobre a realidade que o cerca, buscar aprimoramento contínuo observando padrões éticos de conduta (UNIVERSIDADE FEDERAL DE SÃO CARLOS, 2004).

Considerando os princípios, diretrizes e objetivos do Estágio Curricular Obrigatório do Curso de Biblioteconomia de uma instituição pública de ensino, o estágio tem como objetivo proporcionar ao estudante a participação em situações reais típicas (bibliotecas ou centro de informação), ampliando sua formação acadêmica. (UNIVERSIDADE ESTADUAL DE LONDRINA, 2011). A contribuição está no conhecimento dos diversos serviços de informação, para que o estudante familiarizese com a realidade que se apresenta,ou seja, no estudo, na análise e na avaliação a partir da realidade encontrada e o desenvolvimento de habilidades práticas e a formação ética profissional.

A Biblioteconomia tem, em seus objetivos o planejamento, a organização, a recuperação e a disseminação da informação - deve ter compromisso com a ética profissional, mas também com a ética da informação.

Dentro deste contexto, Lima (2002) observa que a profissão de bibliotecário

[...] se caracteriza como uma profissão de prestação de serviços à sociedade, de comunicação e de contato direto e indireto com o seu público, sendo essa relação com produtores e consumidores de informação determinante para a eficácia dos serviços que presta [...] o bibliotecário está no centro das ações de produção, transferência, uso, reunião, tratamento e difusão das informações por parte das unidades, sistemas e serviços de informação.

Como atribuições da profissão de bibliotecário estão o gerenciamento de bibliotecas e de centros de documentação e de informação, a organização e execução de serviços técnicos específicos, fiscalização de estabelecimentos de ensino de biblioteconomia, organização de serviços de catalogação, classificação e indexação de documentos e materiais bibliográficos, cadastramento de bens, controle e fluxo de informações e documentação, programas especializados e apoio à programação em geral, estímulo e criatividade, sinalização, divulgação e promoção (marketing), registro de produção, de documentos e obras, seleção e aquisição da documentação e material bibliográfico, intercâmbio entre grupos distintos com interesses similares, normalização de documentos, fitotecas, discotecas, programação de dados e de 
palavras, levantamentos bibliográficos, normatização, planejamento e organização de bibliotecas e de centros de documentação e de informação.

Salienta-se que a importância do estágio está no conjunto de atividades voltadas para a aprendizagem da profissão do bibliotecário. Este é o momento em que se desenvolve a aprendizagem prática por meio de participação em situações reais de trabalho, onde ocorrem ações de busca, uso e transferência de informação. O estágio é o aprofundamento sobre as práticas de ensino, nos campos de atuação, tendo como finalidade a formação profissional; a articulação do conhecimento da área em que vai atuar; a instrumentalização do estudante para a ampliação dos conhecimentos adquiridos no cotidiano acadêmico e na prática de ensino; e a vinculação entre conhecimentos teóricos, realidade educacional e social.

\section{ABORDAGEM METODOLÓGICA}

Foi desenvolvido o tema examinando-se aspectos relacionados ao comportamento informacional do estagiário frente ao desenvolvimento das atividades encontradas junto ao estágio curricular, permitindo a elaboração de hipóteses que possam ser pesquisadas em estudos posteriores.

$\mathrm{O}$ estudo em pauta caracteriza-se como pesquisa quantitativa de cunho descritivo - quando há um levantamento de dados, bem como o porquê destes dados; exploratória - a investigação de algum estudo que possui poucas informações e; explicativa - que tem como função informar e explicar a ocorrência de algum fenômeno. (BOENTE; BRAGA, 2004).

O instrumento de coleta de dados utilizado foi um questionário, encaminhado para um universo de 22 alunos matriculados em estágio curricular obrigatório, frequentando a quarta série do curso de Biblioteconomia de uma instituição pública de ensino.

O questionário foi respondido por 20 alunos, o que representa 90,91\% do universo total de pesquisados. Dentre os participantes da pesquisa, 14 são do gênero feminino e seis do masculino. A faixa etária dos participantes compreende a idade média de 28 anos e cinco meses, com idades de 21 a 51 anos. Como recurso para 
postagem e preenchimento do questionário, foi utilizado o Google Docs, que também gerenciou a tabulação dos dados.

\section{RESULTADOS}

O trabalho teve como eixo norteador as três etapas que influenciam o comportamento do indivíduo, segundo Choo (2003) - a necessidade de informação surge quando o indivíduo reconhece vazios em seu conhecimento e em sua capacidade de dar significado a uma experiência. A busca de informação é o momento em que intencionalmente o indivíduo busca informações que possam mudar seu estado de conhecimento e o uso da informação observa-se que quando busca a informação, o indivíduo seleciona e processa, produzindo mudanças em sua capacidade de vivenciar, agir ou reagir a novos conhecimentos.

Algumas tabelas serão apresentadas para visualização, com o intuito de contribuir para o esclarecimento dos resultados apresentados.

No que diz respeito às respostas dos estagiários, foi informado que poderiam marcar mais de uma caixa de seleção, dessa forma a soma das percentagens e os números de respostas pode ultrapassar 100\% e o número de 20 respostas.

\subsection{Necessidades de Informação}

Neste item foram analisados os seguintes dados - a relação da teoria aprendida em sala de aula com a prática no estágio; em que situações o estagiário sentiu necessidade de informação; quando o estagiário reconheceu que uma informação foi necessária para a execução das atividades propostas e; se tomou consciência das suas necessidades de informação para a realização das atividades no estágio.

Os participantes $(95 \%)$ apontaram que percebem a relação da teoria aprendida em sala de aula com a prática, a partir do momento que enfrentaram situações no ambiente de estágio.

Diante dos resultados apresentados constata-se que em seus diversos ambientes como locais de trabalho, o ser humano, ao perceber uma chamada "necessidade de informação", que representa uma "lacuna" em seu estado de 
conhecimento, ou seja, daquilo que sabe e do que deseja saber, busca informações que possam suprir essa necessidade para o seu uso.

Conforme mencionam Amaral, Araújo e Silva (2010, p.4) e permite-se elucidar entre as respostas, que o indivíduo é uma pessoa com conhecimentos, crenças e valores, com necessidades cognitivas, afetivas e fisiológicas. A necessidade de informação é identificada quando o indivíduo percebe que seus conhecimentos “encontram-se insuficientes para lidar com a incerteza, conflito ou demandas surgidas em sua área de estudo ou trabalho". Os ambientes devem proporcionar experiências práticas na formação, devendo o estudante estar em condições de estagiar. Piconez (2001) observa que são as atividades teóricas e práticas que envolvem a totalidade das ações do currículo do aluno.

Com relação às situações no ambiente de estágio, $75 \%$ dos respondentes sentem a necessidade conforme as atividades vão chegando. Constata-se que o comportamento informacional é definido como um processo natural do ser humano no papel de aprendiz, o qual exige o entendimento das relações estabelecidas em determinado espaço-tempo em que ocorrem ações de busca, uso e transferência de informação.

Quando perguntado aos participantes da pesquisa, se houve o reconhecimento quando uma informação foi necessária para o desenvolvimento de suas atividades, os estagiários apontaram como primeira opção, "frequentemente" com 35\%. Como segundas opções (25\%), "sempre" e "na maioria das vezes". O estagiário reconhece a ausência de conhecimento e de sua capacidade de dar sentido a uma experiência.

Outro dado apontado é de que os estagiários entrevistados têm a consciência das necessidades informacionais para a realização das atividades, resultado de $70 \%$. Esta constatação pode ser representada, a partir do momento em que não conseguem resolver problemas. Seguido com $40 \%$ das respostas, quando delegam atividades de outro setor ao qual não estão acostumados.

As necessidades de informação são influenciadas por alguns fatores, entre eles os pessoais, assim como por situações relacionadas com a profissão de cada indivíduo, quando inseridos em um determinado contexto. O estudante aproveita o 
estágio para observar e aprender as atividades que estão sendo vivenciadas. Nesse momento, observa-se a relevância de se aprender fazendo. Quando inserido neste ambiente de estágio, enquanto um espaço colaborativo, é desejável que o estagiário de Biblioteconomia esteja disposto a participar da execução das ações que estão inseridas no papel do bibliotecário, desenvolver habilidades e aprimorar seu conhecimento, aproveitando a oportunidade de aprendizado oferecida durante o período de estágio.

Os resultados (Tabela 1) evidenciam que o ambiente sempre possibilitou a interação na troca de conhecimentos e experiências em um percentual de $70 \%$.

Buriolla (1995) ao afirmar que os conhecimentos adquiridos na prática e a troca de experiências são as melhores formas de aprendizagem. O estagiário tem de ser capaz de interpretar, de recriar e de transformar. O estágio é o momento de desenvolver a aprendizagem prática, o papel profissional e as novas habilidades pessoais e profissionais que auxiliarão este aluno na sua formação.

TABELA 1 - Ambiente e interação na troca de conhecimentos e experiências

Ambiente

Sempre

Tive proximidade apenas de profissionais no setor

Somente interação formal

Outra
$\%$

70,0

$5 \quad 25,0$

$1 \quad 5,0$

0

0

Fonte: Dados da pesquisa

Segundo Choo (2003), as necessidades de informação são analisadas baseadas nas necessidades cognitivas dos indivíduos, representadas por lacunas ou deficiências em um estado de conhecimento mental, que podem ser apresentadas por questões ou tópicos armazenados em sistemas de informação ou em outras fontes. 


\subsection{Busca da informação}

Neste item, foram analisadas as fontes e os canais de informação utilizados pelos estagiários e os recursos de busca para o esclarecimento de dúvidas. Salienta-se que o processo de busca de informações inclui a seleção das fontes de informação, que podem ser consideradas locais, meios ou pessoas, por intermédio dos quais se pode obter informações.

As fontes de informação utilizadas para o desenvolvimento das atividades no estágio curricular, para a maioria (75\%), são os colegas de sala de aula. A internet é utilizada por $70 \%$, enquanto os livros o são por $50 \%$, os artigos por $45 \%$ e os professores por $40 \%$, conforme resultados apresentados na Tabela 2.

A busca da informação é um processo dinâmico constituído tanto pelas ações e necessidades individuais, como pelos recursos sociais e físicos do ambiente no qual o indivíduo usa a informação. Comportamento de busca de informação é o comportamento intencional em função de uma necessidade específica ou para o alcance de um determinado objetivo (WILSON, 2000). Acredita-se que, ao preencher uma lacuna cognitiva, o indivíduo escolhe suas fontes de informação de acordo com o seu conhecimento prévio e pelo resultado alcançado com seu uso anterior.

Conforme exposto por Choo (2003, p. 115) "[...] uma pessoa num estado de espírito investigativo irá explorar mais fontes, enquanto uma pessoa numa atitude indicativa irá buscar informações que levem à conclusão da pesquisa ou à ação.”

TABELA 2 - Fontes de informação no desenvolvimento das atividades

\begin{tabular}{llc} 
Fontes de informação & $\mathbf{f}$ & \% \\
\hline Colegas de sala & 15 & 75,0 \\
Internet & 14 & 70,0 \\
Livros & 10 & 50,0 \\
Artigos & 9 & 45,0 \\
Professores & 8 & 40,0 \\
Revistas & 3 & 15,0
\end{tabular}


Jornal

10,0

2

Outras

10,0

2

Fonte: Dados da pesquisa

Segundo Choo (2003), um indivíduo com necessidade informacional pode preferir evitar uma situação problemática, decidindo não buscar informações, pode também procurar, utilizando o recurso da memória, a informação que necessita. Assim como pode tomar a iniciativa de busca de informação no meio externo. Essa informação também pode ser adquirida por meio de rotinas com a exploração de fontes, como por exemplo, a Internet. Observa-se que há, entre os estagiários entrevistados, o processo de exploração por intermédio de uma ou mais fontes específicas para a obtenção do objeto de interesse.

Comprova-se, de acordo com os resultados acima, o comportamento de busca de informação os estagiários utilizam diversas formas para descobrir e acessar as fontes. Salienta-se que a Internet é considerada um novo meio de comunicação e informação integrada às atividades de ensino e pesquisa. Conforme observam Bartalo, Di Chiara e Contani (2011, p. 9), é necessário conscientizar-se da "autonomia individual na busca de informação, pois ela é fundamental na criação de novos conhecimentos e, consequentemente, na manutenção e aprimoramento das capacidades humanas em todos os aspectos".

A importância da informação e o seu uso dependerão de como o estagiário avalia de forma cognitiva e emocional a informação recebida, assim como os atributos capazes de determinar a pertinência da informação a uma determinada situação problemática. Quando o estagiário, a partir da busca, consegue gerar informações satisfatórias, é provocado nele o sentimento de confiança. No entanto, se a informação não for produtiva, como resultados encontrarão sentimentos de decepção e frustração.

Outro resultado importante encontrado na pesquisa foi o relacionado à forma utilizada como busca de informações. Os participantes da pesquisa utilizam como recurso para o esclarecimento de dúvidas os colegas de trabalho com $75 \%$. Porém, a procura da chefia imediata com $65 \%$ é significativa, com considerável índice de 
respostas, tendo em vista a forma utilizada para alterar seu conhecimento diante do contexto, considerando o nível hierárquico.

Confirma-se que os estagiários, no momento da busca, fazem escolhas sobre onde e como procurar informação. Observa-se que os critérios utilizados levam em consideração a acessibilidade e a relevância da fonte de informação, assim como se pode considerar a credibilidade e a qualidade da informação. Wilson (2000) ressalta que, é pode-se ratificar nas respostas, que fatores referentes à estrutura organizacional e às atividades desenvolvidas relacionadas ao trabalho podem influenciar o comportamento de busca de informação dos indivíduos. Salienta-se que o meio profissional pode estimular ou limitar determinados comportamentos de busca da informação, observa-se que a estrutura hierárquica e o grupo de trabalho influenciaram as atitudes do indivíduo em relação à coleta de informação.

A prática do estágio requer a presença, no ambiente onde se realizará o estágio, de um profissional da mesma área de formação. Ele deverá atuar plenamente no ambiente onde o estudante será inserido. Ao desenvolver atividades que respondem a demandas específicas, esse profissional, na condição de supervisor local de estágio, faz uma ligação significativa entre a instituição formadora e sua categoria profissional. Assim, o estágio não envolveria somente a instituição de ensino e a organização contratante, mas, sobretudo, a categoria profissional na qual o futuro profissional ingressará.

\subsection{Uso da informação}

Neste item, foi analisada a aquisição de informações em sala de aula, atividade que contribui para as atividades no estágio e que atendeu às expectativas em relação à aquisição de novos conhecimentos e experiências para práticas importantes.

Observou-se a partir das respostas dos participantes da pesquisa que as informações adquiridas em sala de aula contribuem frequentemente (40\%) para o desenvolvimento das atividades do estágio. Entretanto, para muitos participantes as informações sempre contribuem para as atividades desenvolvidas com o percentual de $35 \%$. 
$\mathrm{O}$ uso da informação envolve os atos físicos e mentais relacionados à incorporação da informação encontrada e considerada importante, para o conhecimento humano. Segunndo Choo (2003), o uso da informação é o estágio no qual o indivíduo com a informação encontrada age com o objetivo de resolver um problema, tomar decisões ou aumentar a sua compreensão a respeito de uma determinada situação. A forma como a informação será processada e utilizada depende de aspectos cognitivos, da situação emocional relacionada ao processo e ao indivíduo e do contexto organizacional e social dentro do qual acontecerá seu uso.

Para Bousso et. al. (2000, p. 220), "professores e alunos trabalham em aliança, na qual o conteúdo é a matéria prima da aprendizagem, e o que é feito do conteúdo depende do processo vivido pela pessoa do aluno". Esses procedimentos conduzem o aluno a um uso da informação, incluindo o respeito à propriedade intelectual, ou seja, à medida que adquirem o conhecimento, os alunos conquistam sua autonomia em relação à construção do próprio aprendizado.

Outro aspecto importante a ser considerado é (Tabela 3) que o estágio curricular obrigatório contribuiu, de alguma forma, com 55\%, para as expectativas , aquisição e uso de novos conhecimentos e experiência profissional, considerando em $40 \%$ todas as atividades que ele realizou. Este resultado confirma que como consequência, o uso da informação caracteriza-se pela alteração do estado de conhecimento do indivíduo e pela capacidade de ação.

TABELA 3 - Aquisição de novos conhecimentos e experiências

\begin{tabular}{lll} 
Aquisição de novos conhecimentos & f & $\%$ \\
\hline Contribuiu de alguma forma & 11 & \\
& & 55,0 \\
Em todas as atividades que atuei & 8 & \\
Não fez diferença alguma & & 40,0 \\
Outras & 1 & 5,0 \\
\hline
\end{tabular}

Fonte: Dados da pesquisa

Portanto, a importância do estágio está na formação do aluno como um momento específico de aprendizagem, proporcionando a reflexão no âmbito profissional e a visão crítica das dinâmicas na área institucional, ancorados na 
supervisão enquanto processo dinâmico e criativo, tendo em vista contribuir para novos conhecimentos. O estágio não se resume apenas à integração do aluno ao mercado de trabalho ou ao aprimoramento de suas habilidades no campo profissional. Este é o momento em que ele desenvolve a aprendizagem prática, conscientiza-se do papel profissional e altera o comportamento, a partir das necessidades de busca e uso das informações, produzindo novas ações e, consequentemente, novos conhecimentos, assim como habilidades profissionais esperadas para sua formação.

Monteiro e Valentin (2008) ressaltam que o sistema educacional deve acompanhar as tendências atuais, colocando o aprendiz no centro de todo o processo de informação, de forma a aprender a aprender e preparando-o para o mercado de trabalho. O oferecimento de bases que sustentam a formação acadêmica dos estudantes direciona a um aprendizado independente, ao aprender a aprender e à construção do aprendizado ao longo da vida.

\section{CONCLUSÃO}

A relação entre comportamento informacional e o desenvolvimento das atividades no estágio curricular obrigatório é um tema importante para muitos coordenadores e demais educadores, que buscam nos resultados a investigação das necessidades da busca e do uso da informação, visando a uma formação acadêmica e profissional mais adequada às demandas contemporâneas.

A importância do estágio está no conjunto de atividades voltadas para a aprendizagem, momento em que se desenvolve a prática por meio da participação em situações reais de trabalho, e o comportamento informacional do estudante é facilmente identificado por meio da necessidade, da busca, do uso e da transferência de informação.

O estágio, além de uma oportunidade que o acadêmico tem para desenvolver sua carreira e escolha profissional, é a ocasião em que os estudantes estarão em contato com profissionais da área, a fim de ampliar seu conhecimento. Destaca-se que o estágio curricular é a etapa que o estagiário testará seus conhecimentos teóricos, irá refletir e sistematizar o que aprendem durante o curso de graduação. 
Vale a pena ressaltar que um dos resultados da pesquisa, ao buscar informações, os estagiários recorrem aos colegas de trabalho e à chefia imediata, como recurso para o esclarecimento de dúvidas. Menciona Wilson (1999, p. 263) que o comportamento de busca de informação pode envolver outras pessoas, por meio da troca de informações e está relacionado "à variedade de métodos que os indivíduos utilizam para descobrir e ter acesso a fontes de informações”.

Para futuras pesquisas, algumas hipóteses poderiam indicar soluções profícuas no sentido de se conseguir aliar o comportamento informacional às propostas das atividades de estágio visando melhorar a formação profissional. Tais hipóteses podem ser representadas pela conscientização das necessidades informacionais; reflexão sobre a busca da informação no sentido de satisfazer essas necessidades; e um uso mais adequado das informações no desenvolvimento das atividades do estágio. Além disso, investigações dessas mesmas variáveis junto aos profissionais recém-formados que estejam atuando no mercado de trabalho, poderiam elucidar os elementos a serem revistos no estágio.

O comportamento informacional dos estagiários refere-se ao modo como lidam com a informação, incluindo a busca, o uso, a alteração, a troca e o acúmulo que, consequentemente, quando bem administrado, aperfeiçoa-se em aprendizado ao longo da vida. 


\section{REFERÊNCIAS}

ALARCÃO, Isabel (Org.). Formação reflexiva de professores: estratégias de supervisão. Porto: Porto Editora, 1996.

AMARAL, D. M.; ARAÚJO, Eliany Alvarenga de; SILVA, Bruno Rodrigues da. Gestão da informação e comportamento informacional: um estudo de caso no Colégio da Polícia Militar Polivalente Modelo Vasco dos Reis. Revista Brasileira de Segurança Pública, São Paulo, v. 4, n.3. p.1-11, jan./jun. 2010. Disponível em: <http://revista.ssp.go.gov.br/index.php/rebesp/article/view/114/49>. Acesso em: 17 nov 2012.

ANGNES, Juliane Sachser; LIMA, Luiz Fernando de; PAULA, Everson Rodrigo de. A efetividade do estágio supervisionado curricular: um estudo de caso com o curso de secretariado executivo da Unicentro-Guarapuava/Pr. In: SEMINÁRIO MULTIPROFISSIONAL INTEGRADO DE SECRETARIADO DA REGIÃO NORDESTE, 9., 2007, Recife. Anais... Recife: FENASSEC, 2007. Disponível em: <http://www.fenassec.com.br/pdf/artigos_trab_cientificos_ixsemisec_3lugar.pdf> Acesso em: 15 out 2012.

BARTALO, Linete; DI CHIARA, Ivone Guerreiro; CONTANI, Miguel Luiz. Competência informacional e suas múltiplas relações. In: CONGRESSO BRASILEIRO DE BIBLIOTECONOMIA, DOCUMENTAÇÃO E CIÊNCIA DA INFORMAÇÃO, 24., 2011, Maceió. Anais... Maceió: FEBAB, 2011.Disponível em <http://febab.org.br/congressos/index.php/cbbd/xxiv/paper/viewFile/596/411>. Acesso em: 07 set 2012.

BIANCHI, Anna Cecília de Moraes; BIANCHI, ALVARENGA, Marina; BIANCH, Roberto. Manual de Orientação: estagio supervisionado. 4. ed.São Paulo:Cengage Learning, 2011.

BOENTE, Alfredo; BRAGA, Gláucia. Metodologia científica contemporânea. Rio de Janeiro: Brasport, 2004.

BOUSSO, Regina Szylit et al. Estágio curricular em enfermagem: transição de identidades. Revista da Escola de Enfermagem da USP, São Paulo, v. 34, n. 2, Jun. 2000. Disponível em:

<http://www.scielo.br/scielo.php?script=sci_arttext\&pid=S008062342000000200013\&lng=en\&nrm=iso>. Acesso em: $12 \mathrm{dez} 2012$.

BRASIL. Lei $\mathrm{n}^{\text {o. }} 11.788$ de 25 de setembro de 2008. Dispõe sobre o estágio de estudantes; altera a redação do art. 428 da Consolidação das Leis do Trabalho - CLT, aprovada pelo Decreto-Lei no 5.452, de 1o de maio de 1943, e a Lei no 9.394, de 20 de dezembro de 1996; revoga as Leis nos 6.494, de 7 de dezembro de 1977, e 8.859, de 23 de março de 1994, o parágrafo único do art. 82 da Lei no 9.394, de 20 de dezembro de 1996, e o art. 60 da Medida Provisória no 2.164-41, de 24 de agosto de 2001; e dá outras providências. Disponível em: 
http://www.planalto.gov.br/ccivil_03/_ato2007-2010/2008/lei/111788.htm Acesso em: 28 nov. 2012.

BRASIL. Ministério da Educação. Conselho Nacional de Educação. Parecer N. ${ }^{\circ}$ 492/2001 CNE/CES. Diretrizes Curriculares Nacionais dos cursos de Filosofia, História, Geografia, Serviço Social, Comunicação Social, Ciências Sociais, Letras, Biblioteconomia, Arquivologia e Museologia. Aprovado em 03/04/2001. Disponível em: http://portal.mec.gov.br/cne/arquivos/pdf/CES0492.pdf Acesso em: 28 nov. 2012.

BURRIOLLA, Marta A. Feiten. O estágio supervisionado. São Paulo: Cortez, 1995.

CHOO, Chun Wei. A organização do conhecimento: como as organizações usam a informação para criar significado, construir conhecimento e tomar decisões. Tradução de Eliana Rocha. São Paulo: Editora Senac, 2003. 425 p.

DAVENPORT, Thomas H. Cultura e comportamento em relação à informação. In: DAVENPORT, Thomas H. Ecologia da informação : por que só a tecnologia não basta para o sucesso na era da informação. São Paulo: Futura, 1998. Cap. 6, p. 109139.

GASQUE, Kelley Cristine Gonçalves Dias; COSTA, Sely Maria de Souza. Evolução teórico-metodológica dos estudos de comportamento informacional de usuários.

Ciência da Informação, Brasília, DF, v. 39 n. 1, p.21-32, jan./abr., 2010.

LIMA, Raimundo M. Regulamentação e fiscalização profissional: o duplo papel do Conselho Federal de Biblioteconomia. Brasília: CFB, 2002. Disponível em:

<http://www.cfb.org.br>. Acesso em: 28 fev 2013.

MONTEIRO, Nabor Alves; VALEMTIM, Marta Lígia Pomim. Necessidades informacionais e aprendizagem no ciclo de vida de um projeto. Revista Digital de biblioteconomia e Ciência da Informação, Campinas, v. 5, n. 2, p. 53-66, 2008. Disponível em:

<http://www.sbu.unicamp.br/seer/ojs/index.php/rbci/article/view/380>. Acesso em: 27 dez. 2012

PEREIRA, Frederico Cesar Mafra. Necessidades e usos da informação: a influência dos fatores cognitivos, emocionais e situacionais no comportamento informacional de gerentes. Perspectivas em Ciência da Informação, Belo Horizonte, v.15, n.3, p.176194, set./dez. 2010.

PICONEZ, Stela C. Bertholo. A prática de ensino e o estágio supervisionado. 7. ed. Campinas:. Papirus, 2001.

PONTUSCHKA, Nídia Nacib. A formação inicial do professor de geografia. In: FAZENDA, Ivani Catarina Arantes; PICONEZ, Stela C. Bertholo (Coord.). A Prática de Ensino e o Estágio Supervisionado. 7. ed. Campinas: São Paulo: Papiros, 2001. 
SILVA, Marli Vitor da. O comportamento informacional de advogados: um estudo com profissionais que atuam na cidade de Marília e região. 2010.

Dissertação (Mestrado em Ciência da Informação) - Universidade Estadual Paulista, Faculdade de Filosofia e Ciências, Marília. Disponível em < http://www.marilia. unesp.br/Home/Pos-Graduacao/CienciadaInformacao/Dissertacoes/silva_mv_me_ mar.pdf>. Acesso em 06 dez. 2012.

UNIVERSIDADE ESTADUAL DE LONDRINA. Câmara de Graduação. Deliberação n. ${ }^{\circ}$ 012/2011. Aprova o Regulamento Geral do Estágio Curricular Obrigatório do Curso de Biblioteconomia da UEL. Londrina, 2011. Disponível em: <http://www.uel.br/prograd/docs_prograd/deliberacoes/deliberacao_12_11.pdf >. Acesso em: 26 jan 2012.

UNIVERSIDADE FEDERAL DE SÃO CARLOS. Projeto pedagógico do curso de graduação em biblioteconomia e ciência da informação da UFSCAR. São Carlos, 2004. Disponível em <www.dci.ufscar.br/documentos/projeto-pedagogico2013/at_down.>. Acesso em: 28 fev. 2013.

WILSON, Tom D. Models in information Behavior research. Journal of Documentation, London, v. 55, n. 3, p. 249-270, 1999. Disponível em: <http://informationr.net/tdw/publ/papers/1999JDoc.html>. Acesso em: 02 nov. 2012.

WILSON, Tom D. Human Information Behavior. Information Science Research, v. 3, n. 2, p. 50-55, 2000. Disponível em:

<http://ptarpp2.uitm.edu.my/ptarpprack/silibus/is772/HumanInfoBehavior.pdf>. Acesso em: 02 nov. 2012.

WILSON, Tom D. On user studies and information needs. Journal of Documentation, London, v. 62, n. 6, p. 658-670, 2006. Disponível em <http://www.emeraldinsight.com/journals.htm?articleid=1580621>. Acesso em: 31 out. 2012.

Como citar este artigo:

LAGE, Regina Moitinho; SANTANA, Patricia; BARTALO, Linete; ARAÚJO, Carlos Alberto Ávila Araújo. O comportamento informacional no estágio curricular. Rev. digit. bibliotecon. cienc. inf., Campinas, SP, v.12, n.1, p.102-122, jan/abr. 2013. ISSN 1678-765X.

Disponível em: <http://www.sbu.unicamp.br/seer/ojs/index.php/rbci>. Acesso em: 30 jan. 2014. 